\title{
Quick recovery of orientation after magnetic seizure therapy for major depressive disorder
}

George Kirov, Klaus P. Ebmeier, Allan I. F. Scott, Maria Atkins, Najeeb Khalid, Lucy Carrick, Andrew Stanfield, Ronan E. O'Carroll, Mustafa M. Husain and Sarah H. Lisanby

\section{Background}

Magnetic seizure therapy, in which seizures are elicited with a high-frequency magnetic field, is under development as a new treatment for major depressive disorder. Its use may be justified if it produces the antidepressant effects of electroconvulsive therapy (ECT), coupled with limited cognitive side-effects.

\section{Aims}

To evaluate the usefulness of a new $100 \mathrm{~Hz}$ magnetic seizure therapy device.

\section{Method}

We induced seizures with $100 \mathrm{~Hz}$ magnetic transcranial stimulation in 11 patients with major depressive disorder during one session of a regular course of ECT. Recovery times after seizures induced by magnetic seizure therapy and ECT were compared.

\section{Results}

Seizures could be elicited in 10 of the 11 patients.

Stimulation over the vertex produced tonic-clonic activity on 9 out of 11 occasions. Stimulation over the prefrontal midpoint elicited seizures on 3 out of 7 occasions.
The mean duration of magnetically induced seizures was $31.3 \mathrm{~s}$, ranging from 10 to $86 \mathrm{~s}$. All patients had an exceptionally quick recovery of orientation: mean of $7 \mathrm{~min}$ $12 \mathrm{~s}$ (s.d.=2 min $7 \mathrm{~s}$, range $4 \mathrm{~min} 20 \mathrm{~s}$ to $9 \mathrm{~min} 41 \mathrm{~s}$ ). The recovery times were on average $15 \mathrm{~min} 35 \mathrm{~s}$ shorter with magnetic seizure therapy than with ECT in the same patients (paired-samples $t$-test: $P<0.0001)$. Patients reported feeling less confused after magnetic seizure therapy. Side-effects were confined to myoclonic movements, associated with the use of etomidate.

\section{Conclusions}

The new $100 \mathrm{~Hz}$ magnetic stimulator elicits seizures in the majority of patients when administered over the vertex. Magnetic seizure therapy was associated with shorter recovery times and less confusion following treatment. subsequent work will be required to assess the safety and effectiveness of magnetic seizure therapy in the treatment of depression.

\section{Declaration of interest}

None. Funding detailed in Acknowledgements.
Electroconvulsive therapy (ECT) is the most effective treatment for major depressive disorder. ${ }^{1,2}$ However, its use is restricted, mostly owing to concerns about cognitive side-effects. ${ }^{3}$ Modifications to the treatment procedure that could reduce the cognitive side-effect burden are therefore of great clinical interest. Since the introduction of repetitive transcranial magnetic stimulation, it was noticed that a rare side-effect of this treatment was the induction of seizures, when it was used at high frequencies, high intensities, or with long train durations. The possibility and safety of deliberately inducing seizures with repetitive magnetic fields was first tested in non-human primates. ${ }^{4-8}$ In 2000, the first human patient received a course of four magnetic seizure therapy sessions using $40 \mathrm{~Hz}$ at $100 \%$ intensity of the repetitive transcranial magnetic stimulation equipment available at that time. ${ }^{9}$ A second patient was successfully treated with a full course of magnetic seizure therapy with similar parameters. ${ }^{10}$ Both patients tolerated the treatments well and responded to the treatment well. Following this, ten patients with depression received two magnetic seizure therapy sessions each during a course of ECT, in a masked, randomised within-participant cross-over trial. This time a custom-modified device capable of producing $50 \mathrm{~Hz}$ stimulation at a peak magnetic field of $1.2 \mathrm{~T}$ was used. Acute side-effects of magnetic seizure therapy were milder compared with ECT. ${ }^{11,12}$ Although seizures were induced in all patients, it was observed that in three patients the seizure threshold was at the maximum output of the device, highlighting the need for technological improvements in the equipment. Twenty patients with depression were treated with a full course of magnetic seizure therapy using the same $50 \mathrm{~Hz}$ magnetic seizure therapy device in $2003 .^{13}$
Magnetic seizure therapy improved depression scores and patients demonstrated remarkably rapid reorientation with few sideeffects, although improvements were smaller than those seen in the simultaneously treated ECT group. ${ }^{14}$ However, the maximum stimulation of 400 pulses per session was estimated to be on average only 1.3 times the magnetic seizure threshold, perhaps contributing to the suboptimal antidepressant efficacy, similar to some modes of ECT which are highly sensitive to dosage relative to seizure threshold. ${ }^{15}$

These early trials were a proof of the principle that magnetic seizure therapy could induce therapeutic seizures in a clinical setting, but they also indicated the need for improved magnetic seizure therapy devices (as discussed by Lisanby \& Peterchev). ${ }^{16}$ A new prototype device (Magstim Company Ltd, Whitland, Carmarthenshire, Wales) capable of stimulating continuously at $100 \mathrm{~Hz}$ at maximum stimulator output (1.2 $\mathrm{T}$ at the coil surface) for up to $10 \mathrm{~s}$ became available for animal use in 2004. This device was used for the first time in 2004 in a study of rhesus monkeys. ${ }^{16}$ Since then, 275 magnetic seizure therapy sessions have been successfully performed in 11 rhesus monkeys. Seizures have been induced in all sessions and $100 \mathrm{~Hz}$ magnetic seizure therapy still demonstrates fewer cognitive side-effects in the monkey model than conventional ECT. ${ }^{17}$ A version of the $100 \mathrm{~Hz}$ magnetic seizure therapy device designed specifically for human use (the Magstim Theta; Magstim Company Ltd, Whitland, Carmarthenshire, Wales) became available in the middle of 2006. The current study was designed as a pilot to examine the feasibility of magnetic seizure therapy at $100 \mathrm{~Hz}$ in patients, its safety and side-effects, and recovery times compared with ECT. 


\section{Method}

\section{Patients}

Eleven patients diagnosed with treatment-resistant major depressive episodes in the context of either recurrent major depression or schizoaffective disorders according to DSM-IV ${ }^{18}$ criteria, who had been referred for ECT, were enrolled in this pilot study. Demographic details are presented in Table 1. Patients were treated in Whitchurch Hospital, Cardiff, Wales, and the Royal Edinburgh Hospital, Scotland. Eight of the patients were already receiving ECT, and one of their regular (twice weekly sessions) was substituted with magnetic seizure therapy. The remaining three patients received magnetic seizure therapy before ECT: two of these continued with ECT, the third decided against it. Local research ethics committee approval was obtained at both centres and patients gave written informed consent following the approved protocols. In accordance with usual clinical practice of ECT delivery in the UK, antidepressant medication was not stopped during the treatment. Every patient received at least one antidepressant, six were also taking one or more antipsychotics, and two patients (patients 5 and 10 in the table) were also taking sodium valproate.

\section{Magnetic seizure therapy}

We used two custom-built Magstim Theta devices (Magstim Ltd, Whitland, Carmarthenshire, Wales). This stimulator is capable of producing $100 \mathrm{~Hz}$ magnetic stimuli at $1.2 \mathrm{~T}$ (at the centre of the coil) with a biphasic waveform with a pulse width of 340-400 $\mu \mathrm{s}$ for up to $10 \mathrm{~s}$ duration (i.e. a maximum of 1000 pulses). We used a round coil with an $80 \mathrm{~mm}$ average diameter $(47 \mathrm{~mm}$ inside diameter, $115 \mathrm{~mm}$ outside diameter). For positioning of the coil we used standard 10-20 electroencephalogram (EEG) positions. The middle of the coil was applied firmly to the head of the patients, and positioned over $\mathrm{C}_{\mathrm{z}}$ for vertical and $\mathrm{F}_{\mathrm{z}}$ for frontal stimulation for up to $10 \mathrm{~s}$. The direction of current induced in the brain was counter-clockwise. The inside of the coils heats from $20^{\circ} \mathrm{C}$ to $130^{\circ} \mathrm{C}$ after 1000 pulses at $100 \%$ output stimulation; therefore, coils were cooled down to $5-10^{\circ} \mathrm{C}$ in a refrigerator prior to stimulation and were changed if a patient required restimulation. All treatments were given at $100 \mathrm{~Hz}$ frequency and at maximum stimulator output. When a patient was restimulated, we allowed at least $20 \mathrm{~s}$ between stimulations. Staff and patients wore ear protectors during magnetic seizure therapy.

\section{Anaesthesia}

For anaesthesia we used intravenous etomidate $(0.15-0.3 \mathrm{mg} / \mathrm{kg})$ as it does not cause an increase in the seizure threshold and might even reduce it. ${ }^{19}$ Muscle relaxation was achieved with intravenous succinylcholine; since patients recover more quickly from magnetic seizure therapy the dose was generally lower than that routinely used in ECT $(0.5-1.0 \mathrm{mg} / \mathrm{kg}){ }^{14}$

\section{Seizure monitoring}

Seizure duration during magnetic seizure therapy was measured from the start of stimulation to the termination of the observed seizure. ${ }^{12}$ Electroencephalogram seizure expression was monitored via bilateral fronto-mastoid EEG using magnetic resonance imagecompatible plastic electrodes to prevent electrode heating during therapy.

\section{Orientation assessment}

Recovery of orientation after magnetic seizure therapy/ECT was assessed by asking the patient for their name, date of birth, age, place and day of the week. The point of orientation recovery was defined as the time when a patient was able to recall four of these five items.

Table 1 Treatment settings, duration of seizures and recovery of orientation during ECT and magnetic seizure therapy

\begin{tabular}{|c|c|c|c|c|c|c|c|c|}
\hline \multirow[b]{2}{*}{ Patient } & \multirow[b]{2}{*}{$\begin{array}{l}\text { Gender, age } \\
\text { (years), setting }\end{array}$} & \multicolumn{3}{|c|}{ Electroconvulsive therapy } & \multicolumn{4}{|c|}{ Magnetic seizure therapy ${ }^{a}$} \\
\hline & & $\begin{array}{c}\text { Seizure } \\
\text { threshold, mc }\end{array}$ & $\begin{array}{c}\text { Seizure } \\
\text { duration, s } \\
\text { Motor/EEG }\end{array}$ & $\begin{array}{l}\text { Orientation } \\
\text { time, } \\
\text { min:s }\end{array}$ & $\begin{array}{c}\text { Pulses, } \\
n\end{array}$ & $\begin{array}{l}\text { Position } \\
\text { of coil }\end{array}$ & $\begin{array}{c}\text { Seizure } \\
\text { duration, s } \\
\text { Motor/EEG }\end{array}$ & $\begin{array}{l}\text { Orientation } \\
\text { time, } \\
\text { min:s }\end{array}$ \\
\hline 1 & Female, 35, C & $126 \mathrm{BL}$ & $36 / 60$ & $26: 49$ & $\begin{array}{l}250 \\
500\end{array}$ & $\begin{array}{l}\text { Vertex } \\
\text { Vertex }\end{array}$ & $\begin{array}{c}0 / 0 \\
25 / 21\end{array}$ & $\begin{array}{c}- \\
4: 36\end{array}$ \\
\hline 2 & Male, 21, C & $80 \mathrm{BL}$ & $26 / 32$ & $22: 45$ & 500 & Frontal & $86 / 83$ & $5: 23$ \\
\hline 3 & Female, 41, C & $841 \mathrm{BL}$ & $42 / 49$ & $25: 01$ & $\begin{array}{r}250 \\
500 \\
500^{\mathrm{b}} \\
1000^{\mathrm{b}} \\
\end{array}$ & $\begin{array}{l}\text { Vertex } \\
\text { Vertex } \\
\text { Frontal } \\
\text { Frontal } \\
\end{array}$ & $\begin{array}{c}\text { 9.5/NA } \\
\text { 21/NA } \\
0 /- \\
70 / N A\end{array}$ & $\begin{array}{c}- \\
4: 20 \\
- \\
4: 40 \\
\end{array}$ \\
\hline 4 & Female, 47, E & $80 \mathrm{BL}$ & $30 / 42$ & $29: 20$ & $\begin{array}{l}1000 \\
1000\end{array}$ & $\begin{array}{l}\text { Frontal } \\
\text { Vertex }\end{array}$ & $\begin{array}{c}0 / 0 \\
21 / 21\end{array}$ & $\begin{array}{c}- \\
8: 41\end{array}$ \\
\hline 5 & Female, 56, E & $170 \mathrm{BL}$ & $30 / 31$ & $22: 30$ & 1000 & Vertex & $28 / 29$ & $5: 36$ \\
\hline 6 & Female, 28, E & $80 \mathrm{BL}$ & $22 / 38$ & $21: 10$ & $\begin{array}{l}1000 \\
1000 \\
\end{array}$ & $\begin{array}{l}\text { Frontal } \\
\text { Vertex }\end{array}$ & $\begin{array}{l}\text { O/NA } \\
\text { 18/NA }\end{array}$ & $\begin{array}{c}- \\
9: 00 \\
\end{array}$ \\
\hline 7 & Female, 48, E & $204 \mathrm{BL}$ & $33 / 39$ & $28: 00$ & 1000 & Frontal & 22/NA & $8: 43$ \\
\hline 8 & Male, 39, C & No ECT & - & - & $\begin{array}{l}600 \\
600^{b}\end{array}$ & $\begin{array}{l}\text { Frontal } \\
\text { Vertex }\end{array}$ & $\begin{array}{c}0 / 0 \\
15 / \mathrm{NA}\end{array}$ & $\begin{array}{c}\text { 9:00 } \\
\text { no seizure } \\
9: 25\end{array}$ \\
\hline 9 & Male, $28, \mathrm{C}$ & $80 \mathrm{UL}$ & $28 / 28$ & $16: 00$ & 600 & Vertex & $49 / 85$ & 9:41 \\
\hline 10 & Female, 70, C & $80 \mathrm{UL}$ & $54 / 86$ & 13:10 & 600 & Vertex & $0 / 0$ & $\begin{array}{c}\text { 7:48 } \\
\text { no seizure }\end{array}$ \\
\hline 11 & Female, 56, E & $46 \mathrm{UL}$ & 19/NA & $11: 13$ & 1000 & Vertex & $11 / \mathrm{NA}$ & $6: 35$ \\
\hline
\end{tabular}




\section{Results}

The first treatment session with the new device took place in Cardiff in June 2006. The patient was a 35-year-old woman, who had already received five bi-temporal ECT treatments, administered at $195.8 \mathrm{mC}$. For magnetic seizure therapy, the coil was positioned over the vertex $\left(\mathrm{C}_{\mathrm{z}}\right)$. Stimulation with 250 pulses produced no seizure. She was restimulated $52 \mathrm{~s}$ later with 500 pulses and had a visible motor seizure of $25 \mathrm{~s}$; EEG duration was about $21 \mathrm{~s}$, but the end-point was difficult to estimate as there was no post-ictal suppression (EEG trace available from the authors on request).

Orientation was recovered after 4 min $36 \mathrm{~s}$. Immediately upon awakening, the patient achieved a Mini-Mental State Examination ${ }^{20}$ score of $27 / 30$ points. On the next day, the patient's score was at the pre-ECT level of 30 points. A battery of further cognitive tests that included tests for verbal and visual memory, verbal fluency and executive speed was also administered and no relevant changes in performance from baseline were found (results not presented).

We have since treated 10 further patients. In order to explore optimal parameters of stimulation for this new procedure, we applied different numbers of pulses and changed the positioning of the coil between $\mathrm{C}_{\mathrm{z}}$ and $\mathrm{F}_{\mathrm{z}}$. The results for each patient and the corresponding settings for their ECTs are presented in Table 1.

Seizures were elicited in 10 of the 11 patients. The one who did not fit was stimulated with only 600 pulses. Vertex stimulation appeared to be more effective in inducing seizure activity (Table 1 ; see patients 3, 4, 6 and 8). The mean duration of successful seizures was $31.3 \mathrm{~s}$, range $9.5-86 \mathrm{~s}$.

Orientation was recovered much faster after magnetic seizure therapy than after ECT. The mean time to recovery after successful seizures was $7 \mathrm{~min} 12 \mathrm{~s}$ (s.d. $=2 \min 7 \mathrm{~s}$, range $4 \min 20 \mathrm{~s}$ to $9 \mathrm{~min}$ $41 \mathrm{~s})$. We compared these results with the recovery times of the same patients during their nearest ECT session(s) taking care that the order of ECT and magnetic seizure therapy sessions used for the calculation was approximately balanced. The mean recovery time after ECT was $26 \min 35 \mathrm{~s}$. When the recovery times of the nine patients who had both ECT and magnetic seizure therapy were compared in a paired-samples $t$-test, magnetic seizure therapy was shown to result in $15 \mathrm{~min} 35 \mathrm{~s}$ quicker recovery, and despite the small numbers, this result was highly significant at $P<0.0001$.

Patients uniformly commented that they felt less confused after magnetic seizure therapy. Side-effects of $100 \mathrm{~Hz}$ magnetic seizure therapy were restricted to the usual myotonic movements observed after etomidate anaesthesia. No serious immediate adverse events resulted from the use of magnetic seizure therapy.

\section{Discussion}

We report the first use of a new magnetic seizure therapy device capable of sustaining maximum stimulator output for $10 \mathrm{~s}$ at $100 \mathrm{~Hz}$ (1000 pulses). We treated 11 patients with a total of 18 stimulations. To explore the range of seizure thresholds, we used a different number of pulses and two positions of the coil: over vertex $\left(C_{z}\right)$ or pre-frontally $\left(F_{z}\right)$. Seizures were elicited in 10 of the 11 patients. The one who did not fit received only 600 pulses over the vertex. This was a 70-year-old woman who was on valproate; both her age and anticonvulsant medication could account for the difficulty to elicit a seizure. Eight more patients received stimulation over the vertex of between 250 and 1000 pulses. One of these patients (our first patient) did not have a seizure when we used 250 pulses, but she fitted when restimulated at 500 pulses. These findings correspond to the previous observations that the mean seizure threshold with $50 \mathrm{~Hz}$ magnetic seizure therapy was at 268 or 320 pulses. ${ }^{12,14}$

\section{Position of stimulation coil}

We also tested whether stimulation at $100 \mathrm{~Hz}$ was capable of inducing seizures over the prefrontal cortex, which had been difficult to achieve at lower frequencies. ${ }^{9,12,13}$ We attempted seven prefrontal cortex stimulations in six patients. Of those, three were successful (one at 500 and two at 1000 pulses) and four were not successful (one at 500, one at 600, and two at 1000 pulses). Patients who did not fit with prefrontal stimulation fitted when stimulated over the vertex (Table 1). We conclude that even at the maximum setting of the machine, some patients will only fit if the coil is positioned over the vertex (i.e. closest to the motor cortex, which has a lower seizure threshold than the prefrontal or precentral cortices).

\section{Seizure duration and recovery}

We measured seizure duration during magnetic seizure therapy starting from the onset of stimulation. This is because we observed that the seizures in magnetic seizure therapy start during the stimulation train. In contrast, in ECT the convulsion typically does not start during electrical stimulation and a latent phase is usually seen immediately after stimulation. ${ }^{21}$

The mean duration of successful magnetic seizure therapy seizures was $31.3 \mathrm{~s}$, range $10-86 \mathrm{~s}$. Four patients had short seizures of $10,18,15$ and $11 \mathrm{~s}$ (Table 1), which would not be considered therapeutic if evoked by ECT. Two of these patients were stimulated with only 600 pulses, raising the possibility that they may have had adequate seizures if stimulated at the maximum duration output (10s) of the device.

In line with previous results, ${ }^{12}$ the recovery of orientation after magnetic seizure therapy was much faster than after ECT. Despite the small sample size, this difference was highly statistically significant and, more importantly, clinically meaningful. The ability to combine antidepressant efficacy with low neurocognitive adverse effects would be invaluable for patients who require neurostimulation therapies. ${ }^{22}$ All patients felt less confused after magnetic seizure therapy. Many patients felt as if they had received no treatment and remembered details of what had happened immediately prior to the therapy. For instance, patients were able to continue conversations after recovery that had begun just prior to therapy.

\section{EEG changes during seizures}

It has been noted that the EEG after magnetic seizure therapy differs markedly from that after ECT, with a lower amplitude and relative absence of post-ictal suppression. ${ }^{12,14}$ We confirmed these differences after stimulation at $100 \mathrm{~Hz}$. Electroencephalogram traces during ECT showed high amplitude, synchronised EEG activity and clear post-ictal suppression which were markedly different from the EEG recorded after magnetic seizure therapy (traces available on request from the authors). The observed differences between ECT and magnetic seizure therapy ictal expression on EEG could be due to the more focal stimulation achieved with magnetic seizure therapy, which spares deeper brain regions such as the hippocampus that may be implicated in the cognitive side-effects of ECT. ${ }^{6}$ Differences in patterns of seizure expression might also explain the much faster recovery after magnetic seizure therapy. Another explanation for differences in ictal EEG expression between magnetic seizure therapy and ECT may stem from the fact that we were not recording EEG from directly under the magnetic coil, where the induced currents and seizure expression should be at its strongest. Specifically, 
our scalp EEG recordings were collected from bilateral prefrontal cortex, whereas the most effective coil placement was over the vertex. We have since observed that placing the electrodes over the motor cortex during magnetic seizure therapy produces clearer seizure activity, confirming our impression that these seizures are more localised (S. H. Lisanby, personal communication, 2008).

\section{Outlook}

Limitations of this work include the small sample size, open design and non-randomised nature. Nevertheless, this initial pilot study found that magnetic seizure therapy delivered with the new Magstim Theta device was well-tolerated and reliably produced seizures in the majority of patients, while resulting in much less post-ictal confusion. These encouraging initial results beg the question of the efficacy of this new investigational intervention for severe major depression. Previous open studies using $40 \mathrm{~Hz}$ and $50 \mathrm{~Hz}$ magnetic seizure therapy ${ }^{4,14}$ showed promising results, although magnetic seizure therapy did not reach the effect size of optimal ECT. The ability to provide higher-dosage seizures relative to seizure threshold may narrow the gap in efficacy. This will be tested in the context of new trials now underway using the $100 \mathrm{~Hz}$ device to assess the effectiveness and safety of high-dose magnetic seizure therapy relative to ECT.

\begin{abstract}
George Kirov, MRCPsych, PhD, Cardiff University, Henry Wellcome Building, Heath Park, Cardiff; Klaus P. Ebmeier, MD, FRCPsych, University of Oxford, Department of Psychiatry, Warneford Hospital, Oxford, and Andrew Duncan Clinic, Royal Edinburgh Hospital, Edinburgh; Allan I. F. Scott, MB ChB, MBS, MRCPsych, MD, Andrew Duncan Clinic, Royal Edinburgh Hospital, Edinburgh; Maria Atkins, MB BS, MRCPsych, Najeeb Khalid, MCPS, whitchurch Hospital, Cardiff and Vale NHS Trust, Cardiff; Lucy Carrick, MB ChB, MBA, MRCPsych, Andrew Stanfield, MB ChB, MRCPsych, Andrew Duncan Clinic, Royal Edinburgh Hospital, Edinburgh; Ronan E. O'Carroll, BSC (Hons), MPhil, University of Stirling Department of Psychology, Stirling Mustafa M. Husain, MD, Neurostimulation Research Laboratory, Department of Psychiatry, University of Texas Southwestern Medical Center at Dallas, Texas, USA Sarah H. Lisanby, BS, MD, Division of Brain Stimulation and Therapeutic Modulation, Department of Psychiatry, Columbia University College of Physicians and Surgeons, New York State Psychiatric Institute, New York, USA
\end{abstract}

Correspondence: Professor Klaus P. Ebmeier, University of Oxford, Section of Old Age Psychiatry, Warneford Hospital, Oxford OX3 7JX, UK.

Email: klaus.ebmeier@psych.ox.ac.uk

First received 29 Aug 2007, final revision 22 Nov 2007, accepted 28 Feb 2008

\section{Acknowledgements}

We thank the team from the Magstim Company (John H. Starzewski, Andrew Thomas, Anthony Thomas and Reza Jalinous) for constructing the new device and for always responding to our continuous requests for further refinements to the equipment. We than the anaesthetists Mousa Saber Ali, John McClure, Charles Morton, John Wilson and Kate the anaesthetists Mousa Saber All, John McClure, Charles Morton, John Wilson and Kate Gardner and Tracy Fraser who were involved in treating the first patients. These results were presented in part at the 2007 Annual Meeting of the American College of Neuropsychopharmacology, the 2007 Annual Meeting of the Royal College of Psychiatrists and the Medical Research Council Neurosciences Showcase Meeting in 2006.

Support for this work came from the Cardiff and Vale NHS Trust (to G.K., N.K. and M.A.) for the purchase of the Magstim Theta at Cardiff; and from a Trial Platform Grant of the UK Medical Research Council (G0401083) and the Gordon Small Charitable Trust (to K.P.E., R.E.OC and A.S.) for the magnetic seizure therapy trial in Edinburgh. The Magstim Company supported travel for S.H.L. and M.M.H. to attend the first magnetic seizure therapy treatments at Cardiff and Edinburgh. The development and preclinical testing of the prototype $100 \mathrm{~Hz}$ magnetic seizure therapy device were supported by a US National Institute of Health Grant (NIH R01 MH60884 to S.H.L.). S.H.L. and M.M.H. received a grant from the Stanley Medical Research Foundation for a randomised controlled trial of magnetic seizure therapy $v$. ECT. S.H.L. has also received grants to support magnetic magnetic seizure therapy $v$. ECT. S.H.L. has also received grants to support magnetic
seizure therapy development from National Alliance for Research on Schizophrenia and Depression, the American Federation for Aging Research, and New York State Foundation for Science, Technology and Innovation. For other work not the focus of this report, S.H.L. and M.M.H. have received funding from Neuronetics Inc. and Cyberonics Inc. Columbia University has submitted a patent on a novel transcranial magnetic stimulation technology developed in the laboratory of S.H.L. (not the topic of this report). None of the authors hold patents, office, or stock in magnetic seizure therapy or magnetic seizure therapy-related companies.

\section{References}

1 American Psychiatric Association Task Force on Electroconvulsive Therapy. The Practice of Electroconvulsive Therapy: Recommendations for Treatment, Training, and Privileging. APA, 2001

2 Ebmeier KP, Donaghey C, Steele JD. Recent developments and current controversies in depression. Lancet 2006; 367: 153-67.

3 Eranti SV, McLoughlin DM. Electroconvulsive therapy - state of the art. $\mathrm{Br} J$ Psychiatry 2003; 182: 8-9.

4 Lisanby SH, Luber B, Finck AD, Schroeder C, Sackeim HA. Deliberate seizure induction with repetitive transcranial magnetic stimulation in nonhuman primates. Arch Gen Psychiatry 2001; 58: 199-200.

5 Dwork AJ, Arango V, Underwood M, Ilievski B, Rosoklija G, Sackeim HA, Lisanby $\mathrm{SH}$. Absence of histological lesions in primate models of ECT and magnetic seizure therapy. Am J Psychiatry 2004; 161: 576-8.

6 Lisanby SH, Moscrip T, Morales O, Luber B, Schroeder C, Sackeim HA Neurophysiological characterization of magnetic seizure therapy (MST) in non-human primates. Suppl Clin Neurophysiol 2003; 56: 81-99.

7 Moscrip TD, Terrace HS, Sackeim HA, Lisanby SH. Randomized controlled trial of the cognitive side-effects of magnetic seizure therapy (MST) and electroconvulsive shock (ECS). Int J Neuropsychopharmacol 2006; 9: 1-11.

8 Lisanby SH, Sackeim HA, Dwork A, Underwood MD, Wang X, Kassir SA, Luber $B$, Arango V. Effects of electroconvulsive shock and magnetic seizure therapy on mossy fiber sprouting and cellular proliferation in the primate hippocampus. Biological Psychiatry. 2003; 53: 1735.

9 Lisanby SH, Schlaepfer TE, Fisch HU, Sackeim HA. Magnetic seizure therapy of major depression. Arch Gen Psychiatry 2001; 58: 303-5.

10 Kosel M, Frick C, Lisanby SH, Fisch HU, Schlaepfer TE. Magnetic seizure therapy improves mood in refractory major depression. Neuropsychopharmacol 2003; 28: 2045-8.

11 Lisanby SH. Update on magnetic seizure therapy: a novel form of convulsive therapy. J ECT 2002; 18: 182-8.

12 Lisanby SH, Luber B, Schlaepfer TE, Sackeim HA. Safety and feasibility of magnetic seizure therapy (MST) in major depression: randomized withinsubject comparison with electroconvulsive therapy. Neuropsychopharmacol 2003; 28: 1852-65.

13 Lisanby SH, Husain MM, Morales OG, Thornton WL, White PF, Payne N, Rush Aj. Sackheim HA. Controlled clinical trial of the antidepressant efficacy of magnetic seizure therapy in the treatment of major depression. ACNP Annu Meet Abstr 2003; p. 166.

14 White PF, Amos Q, Zhang Y, Stool L, Husain MM, Thornton L, Downing M, McClintock S, Lisanby SH. Anesthetic considerations for magnetic seizure therapy: a novel therapy for severe depression. Anesth Analg 2006; 103: $76-80$.

15 Sackeim HA, Prudic J, Devanand DP, Nobler MS, Lisanby SH, Peyser S, Fitzsimons L, Moody BJ, Clark J. A prospective, randomized, double-blind comparison of bilateral and right unilateral electroconvulsive therapy at different stimulus intensities. Arch Gen Psychiatry 2000; 57: 425-34.

16 Lisanby SH, Peterchev A. Magnetic seizure therapy for the treatment of depression. In Advances in Biological Psychiatry Series Volume 23. Transcranial Brain Stimulation for Treatment of Psychiatric Disorders (eds MA Marcolin, F Padberg): 155-71. Karger, 2007.

17 Peterchev AV, Kirov G, Ebmeier K, Scott A, Husain M, Lisanby SH. Frontiers in TMS technology development: controllable pulse shape TMS (cTMS) and magnetic seizure therapy (MST) at $100 \mathrm{~Hz}$. Biol Psychiatry 2007; 61: S107.

18 American Psychiatric Press. Diagnostic and Statistical Manual of Mental Disorders (4th edn) (DSM-IV). APA, 1994.

19 Khalid N, Atkins M, Kirov G. The effects of etomidate on seizure duration and electrical stimulus dose in seizure-resistant patients during electroconvulsive therapy. J ECT 2006; 22: 184-8.

20 Folstein MF, Folstein SE, McHugh PR. 'Mini-mental state': a practical method for grading the cognitive state of patients for the clinician. J Psychiatr Res 1975; 12: 189-98.

21 Scott AIF. The ECT Handbook. Royal College of Psychiatrists, 2005

22 Sobin C, Sackeim HA, Prudic J, Devanand DP, Moody BJ, McElhiney MC. Predictors of retrograde amnesia following ECT. Am J Psychiatry 1995; 152 995-1001. 